\title{
Mutations in the VMD2 gene are associated with juvenile-onset vitelliform macular dystrophy (Best disease) and adult vitelliform macular dystrophy but not age-related macular degeneration
}

\author{
Franziska Krämer ${ }^{1}$, Karen White ${ }^{1}$, Daniel Pauleikhoff ${ }^{2}$, Andrea Gehrig ${ }^{1}$, Lori Passmore ${ }^{1,3}$, \\ Andrea Rivera ${ }^{1}$, Günther Rudolph ${ }^{4}$, Ulrich Kellner ${ }^{5}$, Monika Andrassi ${ }^{6}$, Birgit Lorenz ${ }^{6}$, \\ Klaus Rohrschneider ${ }^{7}$, Anita Blankenagel ${ }^{7}$, Bernhard Jurklies ${ }^{8}$, Harald Schilling $^{8}$, \\ Florian Schütt ${ }^{7}$, Frank G Holz ${ }^{7}$ and Bernhard HF Weber ${ }^{1}$
}

${ }^{1}$ Institut für Humangenetik, Universität W ürzburg; ${ }^{2}$ St Franziskus Hospital, Münster, Germany; ${ }^{3}$ Department of
Biochemistry, UBC, Vancouver, Canada; ${ }^{4}$ Augenklinik der Universität, M M̈nchen; ${ }^{5}$ Universitäts-Klinikum Benjamin
Franklin, Berlin; ${ }^{6}$ Augenklinik der Universität, Regensburg; ${ }^{7}$ Augenklinik, Heidelberg; ${ }^{8}$ Augenklinik, Essen, Germany

Recently, the VMD2 gene has been identified as the causative gene in juvenile-onset vitelliform macular dystrophy (Best disease), a central retinopathy primarily characterised by an impaired function of the retinal pigment epithelium. In this study we have further characterised the spectrum of VMD2 mutations in a series of 41 unrelated Best disease patients. Furthermore we expanded our analysis to include 32 unrelated patients with adult vitelliform macular dystrophy (AVMD) and 200 patients with age-related macular degeneration (AMD). Both AVMD and AMD share some phenotypic features with Best disease such as abnormal subretinal accumulation of lipofuscin material, progressive geographic atrophy and choroidal neovascularisation, and may be the consequence of a common pathogenic mechanism. In total, we have identified 23 distinct disease-associated mutations in Best disease and four different mutations in AVMD. Two of the mutations found in the AVMD patients were also seen in Best disease suggesting a considerable overlap in the aetiology of these two disorders. There were no mutations found in the AMD group. In addition, four frequent intragenic polymorphisms did not reveal allelic association of the VMD2 locus with AMD. These data exclude a direct role of VMD2 in the predisposition to AMD. European Journal of Human Genetics (2000) 8, 286-292.

Keywords: VMD2; Best disease; bestrophin; adult vitelliform macular dystrophy; age-related macular degeneration; mutation analysis

\section{Introduction}

First described in 1905, the juvenile on set vitelliform macular dystrophy (Best disease-MIM 153700) is an autosomal dominant disorder characterised by a striking accumulation of yellowish material within and beneath the retinal pigment

Correspondence:Bernhard HF Weber, Institut für Humangenetik, Biozentrum, Am-Hubland, D-97074 Würzburg, Germany.

Tel: +499318884062; Fax: +499318884069;

E-mail: bweb@biozentrum.uni-wuerzburg.de

Received 25 June 1999; revised 6 October 1999; accepted 26 October 1999 epithelium (RPE). ${ }^{1}$ With time, the primary egg yolk-like lesions often progress through a series of well described stages including the apparent disintegration of the vitelliform structures. ${ }^{2,3}$ Ultimately, choroidal neovascularisation and/or chorioretinal atrophy occur and are generally associated with severe loss of visual acuity. Although exceptions have been reported, ${ }^{4-6}$ electro-oculography (EOG) is thought to be typically abnormal in Best disease, providing an important diagnostic tool for carrier detection. ${ }^{7,8}$ Both the ophthal moscopic and el ectrodiagnostic features of Best disease suggest the RPE to be the primary site of the defect. 
The gene responsible for Best disease, VMD2, was first localised to chromosome $11^{9,10}$ and subsequently refined to an $980 \mathrm{~kb}$ interval in $11 \mathrm{q} 13$ flanked by polymorphic DNA Ioci D11S4076 and UGB. ${ }^{6,11-16}$ Recently, the VMD 2 gene was identified by positional cloning, and thus far 29 different disease-related mutations have been described. ${ }^{17-20}$ VMD2 is RPE-specific and is comprised of 11 exons coding for a 585 amino acid protein of unknown function. The identification of the disease gene now facilitates research aimed at understanding the pathogenetic mechanism underlying Best disease. It also provides the basis to investigate a potential role of VMD2 in phenotypically related maculopathies.

A dystrophy of the macular fovea was first described by Gass. ${ }^{21}$ Since this first report, the disease has been referred to by numerous names but most commonly as adult foveal macular dystrophy of Gass or adult vitelliform macular dystrophy (AVMD). It is generally accepted as a distinct clinical entity although with highly variable penetrance and expressivity. ${ }^{22}$ Affected individuals have morphological changes very similar to those in Best disease and may or may not have accompanying small druse-like deposits in the paracentral region. ${ }^{21,23}$ AVMD is differentiated from Best disease by a later onset, smaller lesions, slower progression and, most importantly, a slightly subnormal to normal EOG ${ }^{21,24-26}$ Although many cases appear to be sporadic, evidence for autosomal dominant inheritance has been provided. ${ }^{21,22,26}$ Mutations in the peripherin/RDS gene have been found in a small proportion of cases suggesting that AVMD is a genetically heterogeneous phenotype. 27,28

Best disease and AVMD also share some important phenotypic features with age-related macular degeneration (AMD), the leading cause of visual deterioration in the elderly population of industrial ised countries. ${ }^{29,30}$ Clinically, AMD is characterised by druse, abnormal deposits of extracellular material on the inner layers of Bruch's membrane and beneath the RPE, as well as pigment changes, atrophy of the RPE, and choroidal neovascularisation. ${ }^{31,32}$ Similar to Best disease and AVMD, lipofuscin accumulation in the lysosomal compartment of the RPE also appears to be a first and crucial step in the disease aetiology of AMD. Two forms of AMD have been described based on the individual appearance of the druse and the subsequent development of geographic atrophy (atrophic form) or choroidal neovascularisation (exudative form). Exudative AMD represents the most common form of late-stage AMD associated with severe visual loss. The aetiology of AMD is not well understood al though family history, in addition to numerous environmental factors, is known to be a significant risk factor. ${ }^{33-37}$

The present study has two major goals. The first is to analyse the VMD2 gene in a larger series of Best disease patients in order to further characterise the spectrum of disease-causing mutations. This addresses the question of genetic homogeneity vs heterogeneity in Best disease but may also be useful to identify functionally important domains in the protein. Consequently, this may facilitate further studies into the molecular mechanisms underlying Best di sease. The second purpose is to investigate the possible role of VMD2 in the pathogenesis of other maculopathies with overlapping phenotypes, in particular AVMD and the complex AMD.

\section{Material and methods Patients}

Peripheral blood was obtained from 41 unrelated individuals with Best disease. Twenty-five of the probands have a positive family history, whilst 16 probands have an unknown or negative family history of the disease. All individuals were referred from ophthalmologic clinics throughout Germany with the exception of B-29 (UK) and B-30 (Canada).

Samples were also available from single-affected, firstdegree family members of Best disease patients designated as B-12, B-16, B-27, B-41, B-51 and B-52 and from multipleaffected and unaffected family members of patients B-1, B-6, B-7, B-8, B-25, B-29, B-30 and B-45 (Table1). The number of family members participating (affected/total) was: $3 / 4$ for B-1, 9/13 for B-6, 6/8 for B-7, 3/5 for B-8, 7/13 for B-25, 3/3 for $B-29,2 / 4$ for $B-30,4 / 7$ for B-45. At least two generations are represented in all these families.

Peripheral blood was obtained from 32 unrelated individuals with AVMD. Each of these patients has been examined by one of the authors (HS, DP, UK). Twenty-one patients were repeatedly seen at the University Eye Clinic, Essen (Germany), with an average follow-up time of approximately 13 years (ranging between 5 and 46 years). All patients had had periodical photodocumentation, fluorescein angiography and electro-oculography (EOG) in the past. At the time of reexamination, family history, visual acuity, colour vision and EOG were documented. Two probands (A-3 and A-18) reported a family history of AVMD, and for each a DNA sample from one additional first-degree relative was avai lable for genetic analysis. All individuals are of German origin. All have been screened in a previous study and were found to be negative for mutations in the peripherin/RDS gene. ${ }^{28}$

Samples from 200 AMD patients and 140 unaffected controls were included in the study. The AMD group represents the broad clinical spectrum of the disease and contains 100 individuals with geographic atrophy and 100 individuals with exudative AMD of whom 56 have choroidal neovascular membranes and 44 have pigment epithelial detachments (PED). In the latter group tears in the RPE were sometimes observed and were associated with (vascular PED) or without choroidal neovascular membranes (avascular PED). Only patients with unilateral or bilateral late forms of AMD were included but not those with druse only. The control group is comprised of individuals visiting the same clinic as the AMD group but for other reasons. They were examined by fundus examination and only those with less than five hard druse and no other signs of AMD were included in the study. Average age of the AMD group is 75.6 years (ranging from 55 
to 93 years) compared to 79.2 years (ranging from 48 to 102 years) in the control group.

\section{DNA analysis}

For all samples, the ten coding exons of the VMD2 gene were screened by single stranded conformational analysis (SSCA). Genomic DNA was extracted from peripheral blood according to standard techniques. Individual exons were PCR amplified with oligonucleotide primers and conditions as described previously. ${ }^{17}$ PCR products were separated by electrophoresis on a $6 \%$ non-denaturing polyacrylamide gel with or without $5 \%$ glycerol at $4^{\circ} \mathrm{C}$. DNA fragments with mobility shifts were directly sequenced by the PRISM Ready Reaction Sequencing Kit (PE, Applied Biosystems, Weiterstadt, Germany) and an ABI310 automated sequencer.

Genotyping was performed for the families of Best disease patients B-1, B-6, B-7, B-8, B-25, B-29, B-30 and B-45 with the use of highly polymorphic microsatellite markers at D11S956, D11S1765, FTH, and UGB tightly flanking the VMD2 gene. ${ }^{6,15}$ Haplotypes were constructed where additional family members were available and segregation analysis of the disease-associated haplotype was performed (Table1).

Intragenic polymorphisms - $221 \mathrm{~T} \rightarrow \mathrm{C}$, IVS4-24C $\rightarrow$ T, IVS$\mathrm{del}(\mathrm{TCC})_{3}$ and $1410 \mathrm{~A} \rightarrow \mathrm{G}$ have been previously reported ${ }^{17,18}$ and have been determined in the present study for the AMD and age-matched control group.

\section{Results}

\section{Mutation analysis in Best disease}

By SSCA and subsequent direct sequencing a total of 23 unique alterations were identified in 34 Best disease patients (Table1). No mutations were identified in seven patients, six of whom had no or an uncertain history of Best

Table 1 VMD2 mutations in Best disease

\begin{tabular}{|c|c|c|c|c|c|c|}
\hline $\begin{array}{l}\text { Patient } \\
\text { ID }\end{array}$ & $\begin{array}{l}\text { Family } \\
\text { history }\end{array}$ & $\begin{array}{l}\text { Nucleotide } \\
\text { change }\end{array}$ & $\begin{array}{l}\text { Exon/ } \\
\text { Intron }\end{array}$ & $\begin{array}{l}\text { Amino acid } \\
\text { change }\end{array}$ & 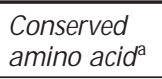 & $\begin{array}{l}\text { Segregation of mutation } \\
\text { (disease haplotype }^{\text {b }}\end{array}$ \\
\hline B-20 & yes & G25A & 2 & V9M & yes & not done \\
\hline B-48 & yes & G28A & 2 & Al0T & no & not done \\
\hline B-30 & yes & C61G & 2 & L21V & no & yes (5-9-2-4) \\
\hline B-47 & unknown & C73T & 2 & $\mathrm{R} 25 \mathrm{~W}$ & yes & n.a. \\
\hline B-43 & yes & C81G & 2 & S27R & yes & not done \\
\hline B-28 & no & A176T & 3 & Q58L & no & n.a. \\
\hline B-3 & yes & C297A & 4 & N99K & no & not done \\
\hline B-51 & yes & C297A & 4 & N99K & no & single-affected relative \\
\hline B-24 & no & T299G & 4 & L100R & no & n.a. \\
\hline B-44 & yes & T299G & 4 & L100R & no & not done \\
\hline B-32 & yes & G422A & 4 & $\mathrm{R} 141^{\mathrm{d}}$ & yes & not done \\
\hline B-29 & yes & G626A & 5 & S209Nc & no & yes (5-9-2-4) \\
\hline B-30 & yes & G626A & 5 & S209N ${ }^{\mathrm{C}}$ & no & yes $(5-9-2-4)$ \\
\hline B-32 & yes & IVS $+1 G \rightarrow$ CIVS & 5 & unknown ${ }^{d}$ & n.a. & not done \\
\hline B-53 & unknown & C652A & 6 & $\mathrm{R} 218 \mathrm{~S}$ & yes & n.a. \\
\hline B-22 & yes & C670A & 6 & L224M & no & not done \\
\hline B-26 & unknown & C670A & 6 & L224M & no & n.a. \\
\hline B-8 & yes & T693G & 6 & S231R & no & yes (6-6-2-6) \\
\hline B-52 & yes & C710G & 6 & T237R & no & single-affected relative \\
\hline B-12 & yes & C728T & 7 & A243V & no & single-affected relative \\
\hline B-27 & yes & C728T & 7 & A243V & no & single-affected relative \\
\hline B-41 & yes & C728T & 7 & A243V & no & single-affected relative \\
\hline B-4 & yes & TCAdel & 8 & 1295del & no & not done \\
\hline B-19 & no & TCAdel & 8 & 1295del & no & n.a. \\
\hline B-21 & yes & TCAdel & 8 & 1295del & no & not done \\
\hline B-23 & yes & TCAdel & 8 & 1295del & no & not done \\
\hline B-35 & no & TCAdel & 8 & 1295del & no & n.a. \\
\hline B-25 & yes & G898A & 8 & E300K & no & yes (12-4-7-3) \\
\hline B-1 & yes & T903G & 8 & D301E & yes & yes (7-11-4-3) \\
\hline B-16 & yes & T903G & 8 & D301E & yes & single-affected relative \\
\hline B-18 & yes & G901A & 8 & D301N & yes & not done \\
\hline B-6 & yes & T929C & 8 & I310T & no & yes (9-7-3-6) \\
\hline
\end{tabular}

amino acids highly conserved in C. elegans, D. melanogaster, and Mus musculus; ${ }^{17,18}{ }^{\text {b}}$ Disease-associated haplotype at markers D11S956, D11S1765, FTH, UGB; 'L21V and S209N segregate together; ${ }^{d}$ R141S and IVS5 $+1 G \rightarrow C$ were found in one patient. Pattern of segregation is unknown. The consequence of the mutation has not been verified; ' ${ }^{2}$ irst-degree relative with the mutation. n.a.: not applicable. 
disease. In contrast, the family of one individual, B-45, was studied in three generations and clearly shows segregation of the disease with the 8-4-2-5 haplotype at markers D11S956, D11S1765, FTH, and UGB (data not shown). In addition to SSCA, the sense and antisense strands of the 10 coding exons of patient B-45 were directly sequenced; however, no diseaseassociated change was identified.

The majority of the mutations found were missense mutations (21/23 distinct mutations). Four missense mutations, V9M , A10T, R218S, D 301E and an amino acid deletion, 1295del, have been previously found in unrelated Best disease patients. ${ }^{17,19,20}$ Another five mutations, R25W, R92S, R218S, E300K and D301N affect the same codons as the mutations R25Q, R92C, E300D, R218C and D301E previously reported to be associated with Best disease. ${ }^{17-20}$ 1295del and A243V appear to be common mutations in our Best disease population. Five $1295 \mathrm{del}$ alleles and three A243V alleles were identified in affected individuals unrelated by genealogy.

Three Best disease patients were found to carry multiple alterations. Individual B-32 has a mutation affecting the invariant GC dinucleotide at the splice donor sequence of exon 5 (IVS5 $+1 \mathrm{G} \rightarrow \mathrm{C}$ ) as well as a mutation at the phylogenetically highly conserved codon 141 (R141H) (Table1). It is unknown whether the two alterations occur on the same haplotype as DNA samples from additional family members were not available for further studies. Patients B-29 and B-30 from the UK and Canada, respectively, have two missense mutations L21V and S209N. In both families segregation analyses demonstrate that the mutations are present on a single allele (data not shown). Furthermore, haplotype analysis with markers at D11S956, D11S1765, FTH, and UGB shows an identical disease haplotype in both families (5-9-2-4) indicating a common founder for the L21V/S209N allele (Table1). No significant differences in severity of phenotype were noted between the three patients with double al terations and the other Best disease patients in this sample.

Segregation analyses demonstrate that the mutations S231R, E300K, D 301E, I310T and V311G are associated with Best disease in the families of patients B-8, B-25, B-1, B-6 and B-7, respectively (data not shown). In addition, haplotype analysis showed a distinct haplotype segregating in each of these families (Table1). In the families where only one additional affected family member was available for study, the identified mutation also occurred with the disease. For example, the D301E mutation was identified in both patient B-16 and his affected sister. Also, N99K and T237R were found in the first-degree relatives of $\mathrm{B}-51$ and $\mathrm{B}-52$, respectively. The A243V missense mutation was identified in probands B-12, B-27, B-41, and their affected first-degree relatives (Table1).

\section{Mutation analysis in AVMD}

Four different missense mutations were present in eight out of 32 unrelated AVMD patients (Table2). Patient A-21 has a replacement of threonine by proline at codon 6 (T6P). This mutation has been previously reported in two families with Best disease. ${ }^{18}$ Similarly, the mutation A243V, identified three times in our Best disease population, is also present in five AVMD patients (B-10, A-13, A-18, A-36, and A-37). Two mutations, each found once, $R 47 \mathrm{H}$ in patient $\mathrm{A}-27$ and D312N in patient A-3 have not been reported previously. Interestingly, the two patients who reported a family history of AVMD, A-3 and A-18, had mutations in the VMD2 gene. The presence of the mutations was confirmed in the available samples from affected first-degree family members.

\section{Mutation analysis in AMD}

No disease-associated alterations were identified in the atrophic and the exudative AMD group. Two silent alterations, both $\mathrm{C} \rightarrow \mathrm{T}$ changes at nucleotide positions 933 and 1023 with no resulting amino acid change, were each detected once in AMD patients but not in the controls (Table3). A moderately polymorphic allele $(C \rightarrow A)$ at nucleotide 219 was identified and was present in similar frequencies in the atrophic and exudative AMD group as well as in the controls (Table3). The frequencies of nucleotide alterations of the four known frequent intragenic polymorphisms $\left(221 \mathrm{~T} \rightarrow \mathrm{C}\right.$, IVS4-24C $\rightarrow$ T, IVS-del $(\mathrm{TCC})_{3}$ and $\left.1410 \mathrm{~A} \rightarrow \mathrm{G}\right)$

Table 2 VMD2 mutations in AVMD

\begin{tabular}{llllll}
\hline $\begin{array}{l}\text { Patient } \\
\text { ID }\end{array}$ & $\begin{array}{l}\text { Family } \\
\text { history }\end{array}$ & $\begin{array}{l}\text { Nucleotide } \\
\text { change }\end{array}$ & Exon & $\begin{array}{l}\text { Amino acid } \\
\text { change }\end{array}$ & $\begin{array}{l}\text { Conserved } \\
\text { amino acid }\end{array}$ \\
\hline A-21 & no & A16C & 2 & T6P & no \\
A-27 & no & G140A & 2 & R47H & no \\
B-10 & no & C728T & 7 & A243V & no \\
A-13 & no & C728T & 7 & A243V & no \\
A-18 & yes & C728T & 7 & A243V & no \\
A-36 & no & C728T & 7 & A243V & no \\
A-37 & no & C728T & 7 & A243V & no \\
A-3 & yes & G934A & 8 & D312N & no
\end{tabular}

${ }^{a}$ Amino acids highly conserved in C. elegans, D. melanogaster, and Mus musculus. ${ }^{17,18}$

Table 3 Frequencies of polymorphisms and rare variants in AMD patients and controls

\begin{tabular}{|c|c|c|c|c|}
\hline $\begin{array}{l}\text { Nucleotide } \\
\text { change }\end{array}$ & $\begin{array}{l}\text { Amino } \\
\text { acid }\end{array}$ & $\begin{array}{l}\text { Atrophic } \\
\text { AMD patients }{ }^{\mathrm{a}}\end{array}$ & $\begin{array}{l}\text { Exudative } \\
\text { AM D patients }{ }^{a}\end{array}$ & $\begin{array}{l}\text { Control } \\
\text { group }\end{array}$ \\
\hline$-221 \mathrm{~T} \rightarrow \mathrm{C}$ & none & $\begin{array}{l}0.29 \\
(57 / 198)\end{array}$ & $\begin{array}{l}0.31 \\
(62 / 200)\end{array}$ & $\begin{array}{l}0.32 \\
(31 / 96)\end{array}$ \\
\hline $219 C \rightarrow A$ & 1731 & $\begin{array}{l}0.07 \\
(13 / 200)\end{array}$ & $\begin{array}{l}0.07 \\
(13 / 200)\end{array}$ & $\begin{array}{l}0.04 \\
(8 / 192)\end{array}$ \\
\hline IVS4-24C $\rightarrow T$ & none & $\begin{array}{l}0.22 \\
(44 / 198)\end{array}$ & $\begin{array}{l}0.26 \\
(52 / 198)\end{array}$ & $\begin{array}{l}0.28 \\
(26 / 94)\end{array}$ \\
\hline IVS6-del(TCC)3 & none & $\begin{array}{l}0.10 \\
(20 / 196)\end{array}$ & $\begin{array}{l}0.08 \\
(16 / 200)\end{array}$ & $\begin{array}{l}0.10 \\
(29 / 278)\end{array}$ \\
\hline $933 C \rightarrow T$ & V311V & $\begin{array}{l}0 \\
(0 / 200)\end{array}$ & $\begin{array}{l}0.01 \\
(1 / 200)\end{array}$ & $\begin{array}{l}0 \\
(0 / 192)\end{array}$ \\
\hline $1023 C \rightarrow T$ & P341P & $\begin{array}{l}0.01 \\
(1 / 200)\end{array}$ & $\begin{array}{l}0 \\
(1 / 200)\end{array}$ & $\begin{array}{l}0 \\
(1 / 192)\end{array}$ \\
\hline $1410 A \rightarrow G$ & T470T & $\begin{array}{l}0.30 \\
(60 / 200)\end{array}$ & $\begin{array}{l}0.30 \\
(59 / 200)\end{array}$ & $\begin{array}{l}0.28 \\
(27 / 96)\end{array}$ \\
\hline
\end{tabular}

${ }^{a}$ Number of alleles is given in parentheses. 
were determined but did not show significant differences between the three study groups (Table3).

\section{Discussion}

We have described 23 unique VMD 2 mutations in 34 of 41 unrelated individuals with Best disease. Of the 25 probands with a positive family history, 24 (96\%) were found to have mutations in the VMD2 gene. Our analysis has not detected a mutation in one proband (B-45) although, by haplotype analysis, the disease appears to be linked to the Best disease locus on 11q13.1 in three generations of affected individuals. The mutation may have remained undetected by our PCRbased detection method used in this study. In particular, we cannot exclude mutations in the promoter or intronic regions or the involvement of larger structural rearrangements. Although similar explanations may account for the remaining six affected individuals in which we were unable to identify a VMD2 mutation, it is important to note that careful pedigree analysis has not established clear evidence of family history of Best disease in any of the six cases. In the absence of this important diagnostic criterion, some of these cases may have been misdiagnosed or may represent phenocopies. In conclusion, our study confirms VMD2 as the gene underlying Best disease and demonstrates that this disorder is a gen etical ly homogenous condition if the diagnosis includes a positive family history. When the individuals with unknown or no family history are considered, the rate of mutation detection decreases noticeably to $69 \%(11 / 16)$ suggesting genetic heterogeneity in this group of sporadic Best disease-like cases.

AVMD has been shown previously to constitute a heterogeneous group of disorders, caused in approximately $18 \%$ of cases by peripherin/RDS mutations. ${ }^{27,28}$ We now provide additional evidence for genetic heterogeneity by identifying four different VMD2 mutations in eight of the 32 individuals (25\%) studied. In all these probands peripherin/RDS was excluded as the disease-causing gene prior to the mutation analysis in the VMD2 gene. ${ }^{28}$ Similar to our findings in Best disease a positive family history appears to be a significant factor for the identification of VMD2 mutations as both individuals with a positive family history of AVMD also had disease-related mutations in VMD2. The large number of patients without known genetic alterations in either the peripherin/RDS or the VMD2 gene strongly argues for the presence of at least a third gene involved in the aetiology of AVMD.

Two of the mutations found in the AVMD group, T6P and $\mathrm{A} 243 \mathrm{~V}$, have also been identified in Best disease ${ }^{18}$ raising the possibility that these patients have been misdiagnosed and in fact may represent atypical cases of Best disease. To address this issue, we have examined the clinical features of individuals with the A243V mutation present in both study groups (Table4). Generally, the EOG is accepted as an important electrodiagnostic tool for the diagnosis of Best disease ${ }^{38,39}$ and is thought to be useful for distinguishing AVMD. ${ }^{40}$ While EOG is typically found to be abnormal in Best disease, ${ }^{38,39}$ the average EOG parameters in AVMD are found to be in the normal range. ${ }^{40}$ In our AVMD patients with the A243V mutation EOGs are normal or only slightly below baseline with the exception of patient A-36 who has clearly subnormal EOGs (Table4). Overall, the EOG values appear to fall into the range typical for AVMD. ${ }^{40}$ In contrast, the Best disease patients with the A243V mutation seem to have higher EOG values than is typically seen in this disorder. In fact, two of the patients, B-12 and his daughter B-46, have EOG values in the normal range whilst those of patient B-27 and his sibling B-36 are only slightly subnormal (Table4). Based on these data it appears that A243V may be a less severe mutation with reduced pen etrance probably obscuring a family history of the disease in many cases. It is important to note that this, in addition to a mild phenotype associated with normal or near-normal EOG values, could lead to misclassification of patients as having AVMD.

Table 4 Clinical phenotype of Best disease and AVMD patients with the A243V missense mutation

\begin{tabular}{|c|c|c|c|c|c|c|}
\hline Patient ID & $\begin{array}{l}\text { Age at } \\
\text { evaluation }\end{array}$ & Family history & $\begin{array}{l}\text { Visual acu } \\
\text { right }\end{array}$ & & Fundus description & $\begin{array}{l}\text { EOG } \\
\text { right/left (baseline) }\end{array}$ \\
\hline \multicolumn{7}{|l|}{ Best disease patients } \\
\hline B-12 & 51 & yes & $20 / 100$ & $20 / 70$ & vitelliruptive & $150 / 160$ (131) \\
\hline B-46 (child of B-12) & 15 & yes & $20 / 20$ & $20 / 25$ & previtelliform & 189/178 (131) \\
\hline B-27 & 30 & yes & $20 / 20$ & $20 / 20$ & vitelliform & 189/149 (200) \\
\hline B-36 (sib of B-27) & 42 & yes & $20 / 40$ & $20 / 100$ & vitelliform & $190 / 172$ (200) \\
\hline B-41 & 67 & yes & $20 / 100$ & $20 / 80$ & vitelliruptive & $120 / 100$ (180) \\
\hline B-42 (child of B-41) & 34 & yes & $20 / 20$ & $20 / 20$ & parafoveal deposits & 134/136 (180) \\
\hline \multicolumn{7}{|l|}{ AVMD patients } \\
\hline B-10 & 32 & no & $20 / 20$ & $20 / 30$ & vitelliruptive & 154/144 (131) \\
\hline A-13 & 52 & no & $20 / 20$ & $20 / 20$ & vitelliform & $139 / 140$ (150) \\
\hline A-18 & 54 & yes & $20 / 400$ & $20 / 400$ & atrophic & $157 / 158$ (150) \\
\hline A-45 (child of A-18) & 33 & yes & $16 / 20$ & $16 / 20$ & small lesion & 139/133 (150) \\
\hline$A-36$ & 56 & no & $20 / 50$ & $20 / 30$ & vitelliruptive & 115/113 (150) \\
\hline A-37 & 41 & no & $20 / 30$ & $20 / 30$ & vitelliruptive & 155/163 (150) \\
\hline
\end{tabular}

${ }^{\mathrm{a} E O G}$ values below baseline are considered pathologic. 


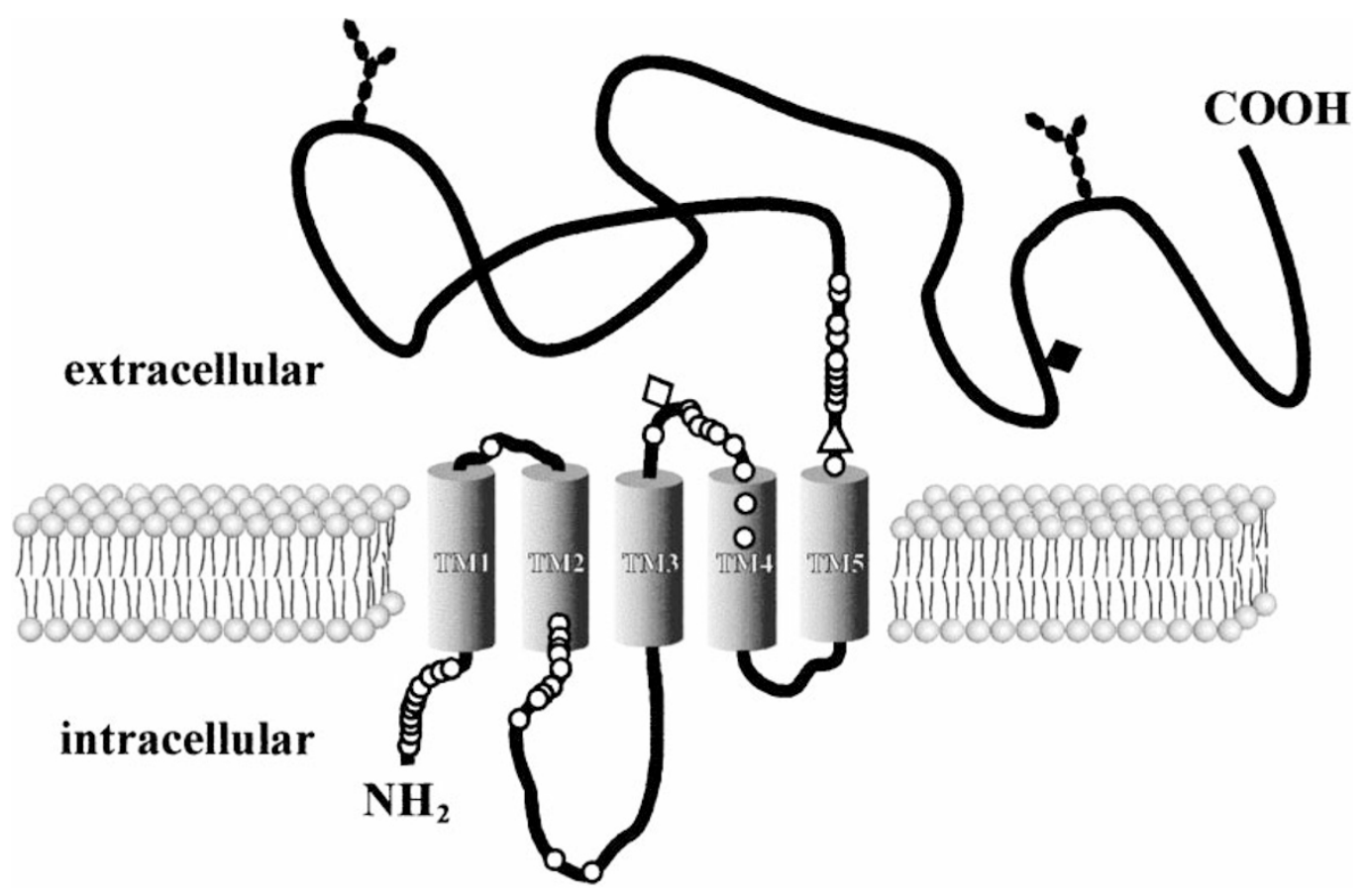

Figure 1 Model of the topological organisation of VM D2 based on biocomputation and the location of the 47 distinct mutations identified in previous studies ${ }^{17-20}$ and this report are shown by open circles (missense mutation), a triangle (in-frame deletion), an open diamond (splice-site mutation) and a filled diamond (out of frame deletion). The sites of possible extracellular $\mathrm{N}$-linked glycosylation at codons 366 and 541 are represented by filled hexagons. TM = transmembrane domain.

Biocomputation predicts that the protein product of the VMD2 gene contains at least four and probably five transmembrane domains. Figure 1 shows a topographical model of VMD2 and provides a relative positioning of the 47 distinct Best disease mutations identified to date ${ }^{17-20}$ (see also this study). Four mutational clusters become evident with the first at the immediate $\mathrm{N}$-terminus (amino acids 6-27), the second in the proposed intracellular loop near the second transmembrane domain (amino acids 85-141), the third in the proposed extracellular loop between the third and fourth transmembrane domains (amino acids 218-235) and the fourth on the extracellular side near the fifth transmembrane domain (amino acids 295-311). These regions may prove to be important in protein function and should be the primary targets for further studies towards the understanding of the molecular mechanisms resulting in Best disease. Interestingly, no missense mutations have yet been found beyond codon 312 , a region representing more than $50 \%$ of the protein. Therefore, this portion of the protein may be less important in the cellular function of VMD2. This is supported by the finding that the C-terminal portion has no known homology to known proteins in the databases, whilst the first half reveals significant sequence identity to a large number of proteins in various species such as C. elegans, D. melanogaster and M. musculus. ${ }^{17,18}$

As with other complex multifactorial conditions, genetic dissection of AMD is a difficult task. Conventional positional cloning strategies rely on model-based linkage analysis to localise the disease gene. This requires large families with several living affected family members and is not feasible in AMD due to its late onset. Therefore, most studies use a candidate gene approach for mutation analyses and association studies using gene loci already implicated in retinal pathology or aging, eg the tissue inhibitor of metalloproteinases- $3,{ }^{41,42}$ the retina-specific ATP-binding cassette transporter $(A B C R)^{43}$ and apolipoprotein E (APOE). ${ }^{44,45}$ Using a similar approach in this study, we evaluated the VMD2 gene but did not identify disease-related mutations in our AMD population. In addition, four common intragenic polymorphisms have not revealed an association between the disease locus and AMD. We therefore conclude that VMD2 does not play a major role in the aetiology of AMD.

In summary, this study demonstrates that mutations in the VMD2 gene are associated with both Best disease and AVMD but not AMD. Furthermore, AVMD appears to be a genetically heterogeneous condition and may include patients with a mild form of Best disease. This study provides an example of the use of genetic analysis to aid in the classification and clinical diagnosis of the retinal dystrophies.

\section{Acknowledgements}

We are grateful to the patients that participated in this study. We would also like to thank $T$ Meitinger (München), Ch Gerth (Regensburg), H Thiele (Halle), U Langenbeck (Frankfurt), D Walker 
(Canada) and S MCDonnell (UK) for providing additional patient samples. This work was supported by the Deutsche Forschungsgemeinschaft (We1259/2-5).

\section{References}

1 Best F: Über eine hereditäre Maculaffektion: Beiträge zur Vererbungslehre. Z Augenheilkd 1905; 13: 199-212.

2 Mohler CW, Fine SL: Long-term evaluation of patients with Best's vitelliform dystrophy. Ophthalmology 1981; 88: 688-692.

3 Deutman AF: Macular dystrophies. In: Ryan SJ, Schachat AP, Murphy RB, Patz A (eds). Retina CV Mosby: St Louis, 1989; pp 243-268.

4 Birndorf LA, Dawson WW: A normal electrooculogram in a patient with a typical vitelliform macular lesion. Invest Ophthalmol 1973; 12: 830-833.

5 Weber BHF, Walker D, Müller B: Molecular evidence for nonpenetrance in Best's disease. J Med Genet 1994; 31: 388-392.

6 Graff C, Eriksson A, Forsman K, Sandgren O, Holmgen G, Wadelius C: Refined genetic localisation of the Best disease gene in $11 q 13$ and physical mapping of linked markers on radiation hybrids. Hum Genet 1997; 101: 263-270.

7 Weleber RG: Fast and slow oscillations of the electro-oculogram in Best's macular dystrophy and retinitis pigmentosa. Arch Ophthalmol 1989; 107: 530-537.

8 Wajima R, Chater SB, Katsumi O, Mehta MC, Hirose T: Correlating visual acuity and electrooculogram recordings in Best's disease. Ophthalmologica 1993; 207: 174-181.

9 Forsman K, Graff C, Nordstrom Set al: The gene for Best's macular dystrophy is located at 11q13 in a Swedish family. Clin Genet 1992; 42: 156-159.

10 Stone E, Nichols BE, Streb LM, Kimura AE, Sheffield VC: Genetic linkage of vitelliform macular degeneration (Best's disease) to chromosome11q13. Nat Genet 1992; 1: 246-250.

11 Graff C, Forsman K, Larsson C et al: Fine mapping of Best's macular dystrophy localises the gene in close proximity to but distinct from the D11S480/ROM1 loci. Genomics 1994; 24: 425-434.

12 Nichols BE, Bascom R, Litt M, M clnnes R, Sheffield VC, Stone EM: Refining the locus for Best vitelliform macular dystrophy and mutation analysis of the candidate gene ROM 1. Am J Hum Genet 1994; 54: 95-103.

13 Weber BHF, Vogt G, Stöhr H, Sander S, Walker D, Jones C: Highresolution meiotic and physical mapping of the Best's vitelliform macular dystrophy (VMD2) locus to pericentromeric chromosome11. Am J Hum Genet 1994; 55: 1182-1187.

14 Weber BHF, Walker D, Müller B, Mar L: Best's vitelliform dystrophy (VMD2) maps between D11S903 and PYGM: No evidence for locus heterogeneity. Genomics 1994; 20: 267-274.

15 Stöhr H, Weber BHF: A recombination event excludes the ROM 1 locus from the Best's vitelliform macular dystrophy region. Hum Genet 1995; 95: 219-222.

16 Hou YC, Richards JE, Bingham EL et al: Linkage study of Best's vitelliform macular dystrophy (VMD2) in a large North American family. Hum Hered 1996; 46: 211-220.

17 Marquardt A, Stöhr H, Passmore LA, Krämer F, Rivera A, Weber BHF: Mutations in a novel gene, VMD2, encoding a protein of unknown properties cause juvenile-onset vitelliform macular dystrophy (Best's disease). Hum Mol Genet 1998; 7: 1517-1525.

18 Petrukhin K, Koisti MJ, Bakall B et al: Identification of the gene responsible for Best macular dystrophy. Nat Genet 1998; 19: 241-247.

19 Bakall B, Marknell T, Ingvast Set al: The mutation spectrum of the bestrophin protein-functional implications. Hum Genet 1999; 104: 383-389.

20 Caldwell GM, Kakuk LE, Griesinger IB et al: Bestrophin gene mutations in patients with Best vitelliform macular dystrophy. Genomics 1999; 58: 98-101.

21 Gass JDM: A clinicopathologic study of a peculiar foveomacular dystrophy. Trans Am Ophthalmol Soc 1974; 72: 139-156.
22 Brecher R, Bird AC: Adult vitelliform macular dystrophy. Eye 1990; 4: $210-215$.

23 Gass JDM: Heredodystrophic disorders affecting the pigment epithelium and retina. In: Klein EA (ed.). Stereoscopic Atlas of Macular Diseases. Diagnosis and Treatment, 3rd edn. CV Mosby: St Louis, 1987, vol 1, pp 246-256.

24 Kingham JD, Lochen GP: Vitelliform macular degeneration. Am J Ophthalmol 1977: 84: 531-536.

25 Ebstein GA, Rabb MF: Adult vitelliform macular degeneration: diagnosis and natural history. $\mathrm{Br} J$ Ophthalmol 1980; 64: 733-740.

26 Vine AK, Schatz H: Adult-onset foveomacular pigment epithelial dystrophy. Am J Ophthalmol 1980; 89: 680-691.

27 Wells J, Wroblewski J, Keen J et al: Mutations in the human retinal degeneration slow (RDS) gene can cause either retinitis pigmentosa or macular dystrophy. Nat Genet 1993; 3: 213-218.

28 Felbor $U$, Schilling $H$, Weber BHF: Adult vitelliform macular dystrophy is frequently associated with mutations in the peripherin/RDS gene. Hum Mutat 1997; 10: 301-309.

29 Hyman L: Epidemiology of eye disease in the elderly. Eye 1987; 1: 330-341.

30 Thompson JR, Du L, Rosenthal AR: Recent trends in the registration of blindness and partial sight in Leicestershire. $\mathrm{Br} J$ Ophthalmol 1989; 73: 95-99.

31 Bressler NM, Bressler SB, Fine SL: Age-related macular degeneration. Surv Ophthalmol 1988; 32: 375-413.

32 Young RW: Pathophysiology of age-related macular degeneration. Surv Ophthalmol 1987; 31: 291-306.

33 Taylor HR, West S, Munoz B, Rosenthal FS, Bressler SB, Bressler NM: The long-term effects of visible light on the eye. Arch Ophthalmol 1992; 110: 99-104.

34 Eye Disease Case-Control Study Group: Risk factors for neovascular age-related macular degeneration. Arch Ophthalmol 1992; 110: 1701-1708.

35 Neely KA, Bressler NM, Bressler SB: Clinical characteristics, epidemiology, and natural history of age-related macular degeneration. Ophthalmol Clin N Am 1993; 6: 291-306.

36 Meyers SM, Greene T, Gutman FA: A twin study of agerelated macular degeneration. Am J Ophthalmol 1995; 120: 757-766.

37 Seddon JM, Ajani UA, Mitchell BD: Familial aggregation of agerelated maculopathy. Am J Ophthalmol 1997; 123: 199-206.

38 Arden GB, Barrada A, Kelsey JH: New clinical test of retinal function based upon the standing potential of the eye. $\mathrm{Br}$ J Ophthalmol 1962; 46: 449-467.

39 Deutman AF: Electro-oculography in families with vitelliform dystrophy of the fovea: detection of the carrier state. Arch Ophthalmol 1969; 81: 305-316.

40 Theischen $M$, Schilling $H$, Steinhorst UH: EOG bei adulter vitelliformer Makuladegeneration (AVMD), schmetterlingsförmiger Patterndystrophie und Morbus Best. Ophthalmologe 1997; 94: 230-233.

41 Felbor U, Doepner D, Schneider U, Zrenner E, Weber BHF: Evaluation of the gene encoding the tissue inhibitor of metalloproteinases-3 in various maculopathies. Invest Ophthalmol Vis Sci 1997; 38: 1054-1059.

42 De La Paz MA, Pericak-Vance MA, Lennon F, Haines JL, Seddon JM: Exclusion of TIMP3 as a candidate locus in age-related macular degeneration. Invest Ophthalmol Vis Sci 1997; 38: 1060-1065.

43 Allikmets R, Shroyer NF, Singh N et al: Mutation of the Stargadt disease gene (ABCR) in age related macular degeneration. Science 1997; 227: 1805-1807.

44 Souied EH, Benlian P, Amouyel P et al: The epsilon4 allele of the apolipoprotein $\mathrm{E}$ gene as a potential protective factor for exudative age-related macular degeneration. Am J Ophthalmol 1998; 125: 353-359.

45 Klaver CCW, Kliffen M, van-Duijn CM et al: Genetic association of apolipoprotein $\mathrm{E}$ with age-related macular degeneration. Am J Hum Genet 1998; 63: 200-206. 